\title{
Glycomimicry: display of fucosylation on the lipo-oligosaccharide of recombinant Escherichia coli K12
}

\author{
Elif Yavuz • Carola Maffioli • Karin Ilg • Markus Aebi • \\ Bernard Priem
}

Received: 9 November 2010/Revised: 6 December 2010 /Accepted: 21 December 2010 /Published online: 1 February 2011

(C) Springer Science+Business Media, LLC 2011

\begin{abstract}
We recently described the design of Escherichia coli K12 and Salmonella enterica sv Typhimurium to display the gangliomannoside 3 (GM3) antigen on the cell surface [1]. We report here the fucosylation of modified lipooligosaccharide in a recombinant E.coli strain with a truncated lipid A core due to deletion of the core glycosyltransferases genes waaO and waaB. This truncated structure was used as a scaffold to assemble the Lewis $\mathrm{Y}$ motif by consequent action of the heterologously expressed $\beta-1,4$ galactosyltransferase LgtE (Neisseria gonorrheae), the $\beta-1,3 N$-acetylglucosaminyltransferase LgtA and the $\beta-1,3$ galactosyltransferase LgtB from Neisseria meningitidis, as well as the $\alpha-1,2$ and $\alpha-1,3$ fucosyltransferases FutC and FutA from Helicobacter pylori. We show the display of the Lewis $\mathrm{Y}$ structure by immunological and chemical analysis.
\end{abstract}

Keywords Bacterial glycosylation - Glycoengineering · Fucosylation - Lewis Y. Chimeric LOS

\section{Abbreviations \\ LPS Lipopolysaccharide \\ LOS Lipooligosaccharide}

\footnotetext{
E. Yavuz $\cdot$ B. Priem $(\bowtie)$ CERMAV-CNRS,

Grenoble, France

E. Yavuz $\cdot$ C. Maffioli $\cdot$ K. Ilg $\cdot$ M. Aebi $(\triangle)$

Institute of Microbiology, ETH,

Zurich, Switzerland

e-mail: aebi@micro.biol.ethz.ch

B. Priem

e-mail: Bernard.Priem@cermav.cnrs.fr
}

\section{Introduction}

Carbohydrates are common molecular tools to mediate interactions between cells. Eukaryotes as well as bacteria and archaea synthesise numerous oligo- and polysaccharide structures, many of which are located on the cell surface. In bacteria, surface carbohydrates are important structural motives involved in many biological processes including virulence, phage protection, and host immunity. The main classes of carbohydrate-containing extracellular compounds are capsular polysaccharides, lipo-oligo/polysaccharides, and to a certain extent, outer membrane glycoproteins $[2,3]$. The unravelling of the respective biosynthetic pathways has opened new strategies to engineer bacterial surfaces. One aspect of this field of research is the engineering of non-pathogenic bacterial strains to display pathogen-related motifs. These newly generated strains can then be used to initiate and study an immune response against carbohydrate structures without any additional harmful effects of the pathogenic strain. Additionally, bacteria can be engineered to express and display carbohydrate motives of a mammalian host for subsequent use in pathogen neutralisation after infection of the host [4, 5]. The engineering of heterologous carbohydrate structures on bacterial cell surfaces in vivo requires several steps: The provision of a donor substrate for the glycosyltransferase(s), the availability of an acceptor structure and the possibility to export the in vivo created foreign carbohydrate structure to the cell surface. The last aspect often prevents the display of engineered oligosaccharides on the cell surface. For example, although the biosynthesis of the lipo-oligosaccharide core of Escherichia coli is well known, the details of the exportation pathway from the cytoplasm to the outermembrane are not completely elucidated. Recently, it 
could be demonstrated that LPS transport involves the periplasmic protein LptA, the cytosolic protein LptB and the inner membrane proteins $\mathrm{LptC}, \mathrm{LptF}$ and $\mathrm{LptG}$, which constitute an $\mathrm{ABC}$ transporter with accessory proteins [6]. The nascent LPS molecule is then targeted to the outer leaflet of the outer membrane by the outer membrane proteins LptD/LptE [7-9].

To create an acceptor substrate for heterologously expressed glycosyltransferases, bacteria with a truncated LOS structure can be obtained by deletion of genes encoding glycosyltransferases involved in the first steps of the lipid A core synthesis. The heterologous expression of glycosyltransferases able to act on such truncated LOS of Escherichia coli R1 allowed surface display of globotriaose (Gb3), lac- $N$-neotetraose (LnNT), and gangliosides GM1 and GM3 [4]. The resulting strains were used as neutralizing bio-agents of the Shiga toxin (Stx) and enterotoxic E. coli [5]. Another possibility is to build the heterologous carbohydrate structure on the lipid linker undecaprenylphosphate, with a subsequent transfer of this structure to a full lipid A core by the O-antigen ligase WaaL. For example, the overexpression of Haemophilus influenzae genes encoding glycosyltransferases in E. coli resulted in the endogenous synthesis of a recombinant LOS carrying Haemophilus LPS motifs [10]. Altogether, these data show that the lipid A export system of E. coli has a certain flexibility towards its substrate and is able to transport foreign structures to the outer membrane. However, none of the chimeric LOS structures reported above contain fucose, an important monosaccharide involved in cell recognition. On the host side, fucose forms part of a target for a number of pathogens such as Pseudomonas aeruginosa, or Campylobacter jeujuni [11, 12]. On the bacterial side, fucose is for example present on the gastric pathogen Helicobacter pylori.

Our recent work focused on the glyco-engineering of $E$. coli to produce recombinant oligosaccharides [11]. The technology is based on the internalisation of $\beta$-galactosides such as lactose followed by endogenous glycosylation when glycosyltransferases from other bacteria were expressed recombinantly. With this system, we successively achieved the synthesis of fucosylated oligosaccharides including the human Lewis $\mathrm{X}$ and $\mathrm{H}$ antigens [13-16]. Additionally, the co-expression of $\alpha 1,2$ - and $\alpha 1,3$ - fucosyltransferases of $H$. pylori led to the production of oligosaccharides carrying the Lewis $\mathrm{Y}$ antigen [17], which is a structural motif of the lipooligosaccharide of H. pylori [18], and a tumor-associated antigen in humans [19].

In the present report, we addressed the fucosylation of the LOS of Escherichia coli K12 with $\alpha 1,2$ - and $\alpha 1,3-$ fucosyltransferases of $H$. pylori. A double mutant over-expressing a $\beta$-galactosyltransferase of Neisseria gonorrhoea was designed in order to exhibit a terminal lactosyl motif at the distal moiety of lipid A. The recombinant enzymes previously used in our lab to produce fucosylated oligosaccharides from lactose were over-expressed in that strain in order to glycosylate the lactosyl-lipidA core. Chemical analyses and immunological assays were performed and attested for synthesis and exportation of the Lewis Y epitope Fuc $\alpha-2$ Gal $\beta-4[$ Fuc $\alpha-3]$ GlcNAc $\beta-3 \mathrm{Gal}(\mathrm{Fuc}=$ fucose, $\mathrm{Gal}=$ galactose, $\mathrm{GlcNAc}=$ $N$-acetylglucosamine) amongst other glycoforms.

\section{Materials and methods}

Bacterial strains and growth conditions

A summary of bacterial strains used in this study can be found in Table 1. Bacteria were grown in Luria-Bertani (LB) medium (10 g/l Bacto tryptone, $5 \mathrm{~g} / 1$ Bacto yeast extracts, $5 \mathrm{~g} / 1 \mathrm{NaCl}$ ). LB agar plates were supplemented with $1.5 \%$ $(\mathrm{w} / \mathrm{v})$ agar. Antibiotics were used at the following final concentrations: Tetracyclin $10 \mu \mathrm{g} / \mathrm{ml}$, ampicillin $100 \mu \mathrm{g} / \mathrm{ml}$, kanamycin $50 \mu \mathrm{g} / \mathrm{ml}$, chloramphenicol $25 \mu \mathrm{g} / \mathrm{ml}$.

Construction of the E. coli K-12 $\Delta$ wcaJ $\Delta$ waaO $\Delta$ waaB strain LPS1

To inactivate $w c a J$, primers $(\mathrm{a}+\mathrm{b})$ (Table 1$)$ were used for PCR amplification of $0.64 \mathrm{~kb}$ of DNA flanking the $5^{\prime}$ end of wcaJ from JM107, whereas primers $(\mathrm{c}+\mathrm{d})$ were used for PCR amplification of $1.27 \mathrm{~kb}$ of DNA flanking the $3^{\prime}$ end of $w c a J$. The reverse sequence of primer (c) was contained in primer (b), allowing a fusion of both DNA fragments by PCR amplification with primers $(a+d)$. Fused DNA of $1.91 \mathrm{~kb}$ containing a truncated $w c a J$ was cloned into $B a m H I$ site of the suicide plasmid pKO3. The resulting recombinant suicide plasmid pKO3-J containing a truncated wcaJ sequence and flanking DNA to guaranty recombination was transformed into TA1 cells, mutants were obtained according to author's instructions [20]. Positive clones were screened by PCR with primers (a) and (c). The inactivation of $w a a O$ and $w a a B$ is described elsewhere [1].

\section{Construction of plasmids pSUlgtA and pSU-lgtAfutC}

Plasmid pLNT1T [16] was digested with NdeI to remove $\lg t B$, thus ligated, providing pBBR-lgtA. LgtA was then obtained by $K p n \mathrm{I}$ and $X b a \mathrm{I}$ digestion for the cloning into pSU2718 to give pSU-lgtA. FutC was obtained by KpnI and SalI digestion of plasmid pEXT20futC [14] and subcloned into pBluescript KS, thus giving pBS-futC. This plasmid was then digested with $X b a \mathrm{I}$ to obtain $f u t C$ flanked by two $X b a \mathrm{I}$ sites, allowing a cloning into $X b a \mathrm{I}$ site of $\mathrm{pSU}$-A to give $\mathrm{pSU}$-lgtAfutC. 
Table 1 Bacterial strains, plasmids and oligonucleotides used in this study

\begin{tabular}{|c|c|c|}
\hline \multicolumn{3}{|c|}{ Escherichia coli strains } \\
\hline Name & Genotype and phenotype & Source or reference \\
\hline DH5 $\alpha$ & $\begin{array}{l}\text { SupE44 } \Delta \text { lac } U 169(\Phi 80 \text { lacZ } \Delta \mathrm{M} 15) \text { hsdR } 17 \text { recA1 endA } 1 \\
\text { gyrA96 thi-1 relA } 1\end{array}$ & {$[21]$} \\
\hline JM107 & 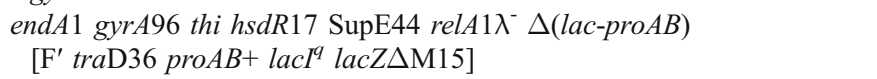 & DSM; [22] \\
\hline TA01 & JM $107 \Delta$ nanA & {$[23]$} \\
\hline LPS1 & TA01 $\Delta w c a J \Delta w a a O B$ & {$[1]$} \\
\hline H type II & LPS1 with pBBRlgtE, pSUlgtAfutC, pWKSlgtB & This work \\
\hline LX & LPS1 with pBBRlgtE, pSUlgtA, pWKSlgtB, pBSfutA & This work \\
\hline LY & LPS1 with pBBRlgtE, pSUlgtAfutC, pWKSlgtB, pBSfutA & This work \\
\hline \multicolumn{3}{|l|}{ Plasmids } \\
\hline Plasmid & Genotype & Source or reference \\
\hline pKO3 & $\begin{array}{l}\text { Suicide plasmid, temperature-sensitive } \mathrm{pSC} 101 \text { replication origin, } \\
\text { sacB (levansucrase) }\end{array}$ & {$[20]$} \\
\hline $\mathrm{pKO} 3-\mathrm{BO}$ & Truncated waaOB genes and flanking DNA cloned into pKO3 & This work \\
\hline pBBRlgtE & $\operatorname{Tet}^{R}$, bhr derivative, $N$. gonorrhoeae lgtE cloned into pBBR1MCS-3 & {$[1]$} \\
\hline pBSfutA & $A m p^{R}$, pbr322 derivative, $H$. pylori futA cloned into pBlue Script II KS & {$[11]$} \\
\hline pWKSlgtB & $\mathrm{Kan}^{R}$, pWKS130 derivative carrying $\lg t B$ & {$[24]$} \\
\hline pSU2718 & $\mathrm{Cam}^{R}$, pACYC184 derivative. & {$[25]$} \\
\hline pSUlgtA & N. meningitidis lgtA cloned into pSU2718 & This work \\
\hline pSUlgtAfutC & H. pylori futC cloned into pSUlgtA & This work \\
\hline \multicolumn{3}{|c|}{ Oligonucleotides $\left(5^{\prime} \rightarrow 3^{\prime}\right)$} \\
\hline a & CAAGGATCCAGATGACAAATCTAAAAAAGCGCGA & \\
\hline $\mathrm{b}$ & $\begin{array}{l}\text { TGCGTGCGGACGTGGACCGACAATCCGTTTCGCGTCCT } \\
\text { CGACCAG }\end{array}$ & \\
\hline $\mathrm{c}$ & ATTGTCGGTCCACGTCCGCACC & \\
\hline $\mathrm{d}$ & TTAATTTGGATCCAATCGGGTTACCTACGGAGC & \\
\hline
\end{tabular}

\section{Cell-based ELISA}

Bacterial cultures that had been induced overnight with $0.6 \mathrm{mM}$ IPTG were equalized to $2 \mathrm{OD}_{600} / \mathrm{ml}$ with PBS. Flat-bottom ELISA plates were coated with $50 \mu \mathrm{L}$ of cells and fixed by addition of $20 \mu \mathrm{L}$ of formaldehyde for $30 \mathrm{~min}$ at room temperature. Afterwards, the formaldehyde was removed and unspecific binding was blocked by addition of $1 \%(\mathrm{w} / \mathrm{v})$ BSA in PBS for $1 \mathrm{~h}$ at room temperature. The blocking agent was then removed and the cells were incubated for $1 \mathrm{~h}$ at $4^{\circ} \mathrm{C}$ with anti-Lewis $\mathrm{Y}$ antibody (Abcam) in $0.1 \%(\mathrm{w} / \mathrm{v}) \mathrm{BSA}$ in PBS. After four washing steps with $0.05 \%$ Tween-20/PBS, the bound anti-Lewis-Y antibody was detected by incubation of the cells with an anti-mouse-IgM-HRP conjugate (Santa Cruz) for $45 \mathrm{~min}$ at room temperature. Unbound HRPconjugate was washed away with $0.05 \%$ Tween-20/PBS in four washing steps before the cells were resuspended in $200 \mu \mathrm{l}$ ABTS solution (2,2'-azino-bis(3-ethylbenzthiazoline-6-sulphonic acid, final concentration $1 \mathrm{mM}$ in $70 \mathrm{mM}$ phosphocitrate buffer $\mathrm{pH} 4.2$ with addition of $1 \%$ $\mathrm{H}_{2} \mathrm{O}_{2}$ ). $\mathrm{V}_{\max }$ was determined by recording the color development at $405 \mathrm{~nm}$ for $5 \mathrm{~min}$ in a SpectraMaxPlus (Molecular Devices).

Electrophoretic analysis of chimeric LOS by SDS-PAGE and immunological detection

The equivalent of $1 \mathrm{OD}_{600}$ of exponentially growing induced cultures with $0.6 \mathrm{mM}$ IPTG was pelleted and resuspended in $500 \mu \mathrm{l} 0.065 \mathrm{M}$ Tris- $\mathrm{HCl} \mathrm{pH}$ 6.8, 2\% SDS $(\mathrm{w} / \mathrm{v}), 5 \% \beta$ - Mercaptoethanol (v/v), 10\% Glycerin (v/v), $0.05 \%$ Bromophenol blue $(\mathrm{w} / \mathrm{v})$ and lysed for $5 \mathrm{~min}$ at $95^{\circ} \mathrm{C}$. After cooling to room temperature, proteins were digested by addition of proteinase $\mathrm{K}$ (Roche, final concentration $0.4 \mathrm{mg} / \mathrm{ml}$ ) for $1 \mathrm{~h}$ at $60^{\circ} \mathrm{C}$. Equal volumes of each sample were then separated on a $17 \%$ Tris-Tricine-PAGE and stained with silver as described [26].

To detect LewisY structures in the chimeric LOS after gel electrophoresis, a monoclonal anti-LewisY antibody (Abcam) was used. Bound anti-LewisY was visualised with a goat-anti-mouse-IgM-HRP conjugate (Santa Cruz) and ECL (Amersham) as recommended by the manufacturer. 
Isolation of lipooligosaccharides

Isolation of LOS was carried out by phenol/chloroform/ petrol ether as reported [27], except that it was recovered from the phenol phase by precipitation with 6 volumes of diethyl ether/acetone $(1: 5 \mathrm{v} / \mathrm{v})$ as described [28].

Preparation of de- $O$-acylated LPS

De-O-acylation was obtained by conventional mild hydrazinolysis except that hydrazine-hydrate was used instead of anhydrous hydrazine. The solution $(20 \mathrm{mg}$ $\mathrm{LOS} / \mathrm{ml}$ ) was stirred at $37^{\circ} \mathrm{C}$ for $2 \mathrm{~h}$. De- $O$-acylated LOS was recovered from the hydrazine phase by precipitation with 15 volumes of ice-cold acetone. The pellet was recovered by centrifugation, washed with acetone and air-dried.

Mass spectrometry analysis

MALDI-MS spectra of the sample were obtained with an Autoflex Bruker MALDI-TOF spectrometer. DHB (2, 5-Dihydroxybenzoic acid, SIGMA) was used as a matrix. The De-O-acylated LOS sample was dissolved in water at a concentration of $0.4 \mathrm{mg} / \mathrm{mL}$, DHB at $50 \mathrm{mg} / \mathrm{ml}$ in methanol. One $\mu$ of each solution was loaded and mixed directly on the target by the dried droplet method. The analysis was performed in the linear negative ion mode with an accelerating voltage of $20 \mathrm{kV}$ and an extraction delay of 90-80 nsec. Spectra were calibrated externally using a peptides mix standard from Bruker Daltonics.

\section{Methylation linkage analysis}

The LOSs (about $70 \mathrm{mg}$ ) were degraded with $0.1 \mathrm{M}$ sodium acetate buffer, $\mathrm{pH} 4.2$, at $100^{\circ} \mathrm{C}$ for $4 \mathrm{~h}$ to cleave the acidlabile ketosidic linkage between the core OS and lipid A. The water-insoluble lipid A was removed by centrifugation at $20,000 \mathrm{~g}$ for $20 \mathrm{~min}$. The oligosaccharide fraction was precipitated from the soluble phase by adding 4 vol of $-20^{\circ} \mathrm{C}$ acetone [29]. Samples were centrifuged at $13,000 \mathrm{~g}$ at $4^{\circ} \mathrm{C}$ for $20 \mathrm{~min}$, and the salt-containing $80 \%$ acetone supernatant was discarded. The pellet was dried, solubilised in dimethylsulfoxide, and methylated with methyl iodine [30]. Permethylated oligosaccharides were hydrolysed in $3 \mathrm{M}$ trifluoroacetic acid for $3 \mathrm{~h}$ at $100^{\circ} \mathrm{C}$. Methylated sugars were analysed after reduction using $\mathrm{NaBD}_{4}$ and acetylation with an equal mixture of acetic anhydride and pyridine. Partially methylated alditol acetates (PMAA) were analysed by GC-MS using an agilent chromatograph 6850 equipped with a 5975C MS detector. The neutral sugars and the glucosamine derivatives were separated on a SP2380 column and a HP5-MS column, respectively.

\section{Results}

Engineered E. coli overexpressing fucosyltransferase-genes from $H$. pylori produced the Lewis Y epitope and presented it on the cell surface

In our previous work, a mutant of E. coli K12 synthesizing a glucose-terminal truncated lipid A core was prepared by inactivation of glycosyltransferases genes waaO and waaB [1]. To construct strains displaying fucose-containing structures, we additionally deleted wcaJ involved in the assembly of colanic acid synthesis, thus providing GDPfucose availability under over-expression of the positive regulator of the CPS operon (capsular polysaccharide) named Rcsa [16]. The resulting strain was termed LPS1. Five glycosyltransferase genes necessary for the display of the Lewis $\mathrm{Y}$ antigen from different bacterial sources were expressed heterologously: lgtE, encoding a $\beta 1,4$-galactosyltransferase of Neisseria gonorrhoea reported to transfer to glucose in the LOS structure of $N$. gonorrhoea [31]; lgtA from Neisseria meningitidis encoding a $\beta 1,3-N$-acetylglucosaminyltranferase with galactose as an acceptor, and $\lg t B$, encoding a $\beta 1,3$-galactosyltranferase with $N$-acetylglucosamine as an acceptor, also from $N$. meningitidis [32]. In addition, futA and futC, encoding $\alpha 1,3-$ and $\alpha 1,2-$

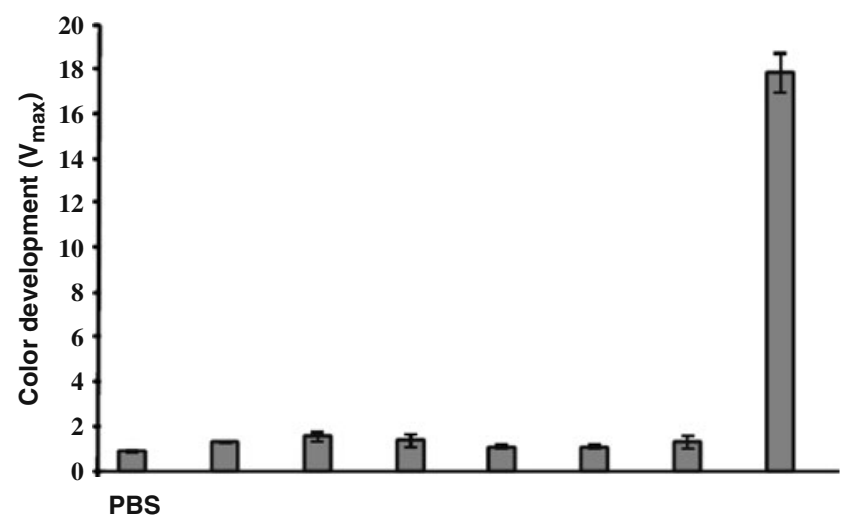

\begin{tabular}{|c|c|c|c|c|c|c|c|c|}
\hline \multirow{5}{*}{ 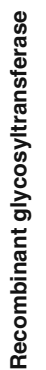 } & LgtE & - & + & + & + & + & + & + \\
\hline & LgtA & - & - & + & + & + & + & + \\
\hline & LgtB & - & - & - & + & + & + & + \\
\hline & FutC & - & - & - & - & + & - & + \\
\hline & FutA & - & - & - & - & - & + & + \\
\hline
\end{tabular}

Fig. 1 Cell based ELISA for the quantification of Lewis Y display on $\mathrm{LeY}$ cells using a monoclonal anti-Lewis $\mathrm{Y}$ antibody. From left to right: 1, no cells; 2, LPS1 cells; 3, LPS1 + pBBRlgtE; 4, LPS1 + pBBRlgtE + pSUlgtA; 5, LPS1 + pBBRlgtE + pSUlgtA + pWKSlgtB; 6, H type II cells; 7, LX cells; 8, LY cells 


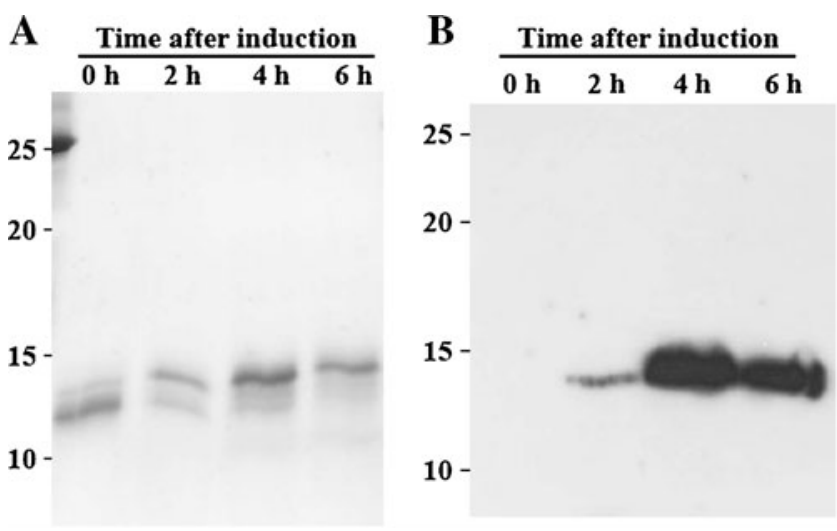

Fig. 2 Silver-staining (A) and immunoblot analysis with a monoclonal antibody against Lewis Y (B) of proteinase K-treated whole cell extracts from the LY E. coli strain during a time-course experiment

fucosyltransferases of Helicobacter pylori, respectively, were expressed [14-16]. The transformation of the E. coli mutant strain LPS1 with compatible plasmids carrying the five glycosyltransferase genes should result in the production of a modified LPS that terminates in the Lewis Y motif Fuc $\alpha-2$ Gal $\beta-4[$ Fuc $\alpha-3]$ GlcNAc $\beta-3$ Gal. To test this hypothesis, a cell-based enzyme immunosorbent assay was carried out with a Lewis Y specific monoclonal antibody. Microtiter plate wells were coated with E. coli cells LPS1, $\mathrm{H}$ type II, LX and LY as listed in Table 1, expressing intermediate glycan structures between the truncated LOS and the Lewis Y motif. Only the LY cells expressing all necessary enzymes for Lewis $\mathrm{Y}$ synthesis led to a significant signal (Fig. 1). These data indicated the display of the Lewis $\mathrm{Y}$ motif at the surface of the recombinant strain LY.

In order to visualize glycosylation of the truncated LOS acceptor by apparent molecular weight increase of the LOS in gel electrophoresis, a time-course experiment was carried out with the recombinant strain expressing the glycosyltransferases necessary for display of the Lewis Y motif. Cell lysates of these cells were then prepared and analysed by Tris-Tricine polyacrylamide gel electrophoresis followed by silver stain (Fig. 2a) and immunoblot (Fig. 2b). The addition of monosaccharides on the LOS acceptor structure was clearly visible by the appearance of bands with higher apparent molecular weight over time as can be seen in the silver nitrate stained gel which correlated with recognition by the anti-Lewis Y monoclonal antibody in the immunoblot analysis. Several bands of an apparent molecular weight intermediate of the truncated lipid A core and the Lewis $\mathrm{Y}$ carrying lipid A core could be observed in the silver nitrate staining (Fig. 2a), which suggested some heterogeneity in the glycosylation profile, although a single band was detected by the antibody (Fig. 2b).

Chemical analyses revealed presence but low abundance of Lewis Y motif due to the broad specificity of the $\alpha 3$-fucosyltransferase of $H$. pylori

In order to correlate the immunological description of the strains generated to a chemical characterization of recombinant LOSs, MALDI-TOF mass spectrometry analysis was conducted with de-O-acylated LOSs of the different $E$. coli strains. This technique was proven to be suitable to

Table 2 Methylation linkage analysis of the core oligosaccharides released by mild hydrolysis from recombinant lipo-oligosaccharides

\begin{tabular}{|c|c|c|c|c|}
\hline \multirow[t]{2}{*}{ Derivative $^{\mathrm{a}}$} & \multirow[t]{2}{*}{ Assignment } & \multicolumn{3}{|c|}{ Relative detector response ${ }^{\mathrm{b}}(\%)$} \\
\hline & & H type II & LX & LY \\
\hline $1,5-\mathrm{Ac}_{2}-2,3,4-\mathrm{Me}_{3}$-fucitol & terminal Fuc & 7.9 & 11.4 & 10.0 \\
\hline $1,5-\mathrm{Ac}_{2}-2,3,4,6-\mathrm{Me}_{4}$-glucitol & terminal Glc & 8.7 & 26.0 & 6.0 \\
\hline $1,5-\mathrm{Ac}_{2}-2,3,4,6-\mathrm{Me}_{4}$-galactitol & terminal Gal & 14.8 & 13.6 & 23.0 \\
\hline 1,3,5- $\mathrm{Ac}_{3}-2,4,6-\mathrm{Me}_{3}$-galactitol & 3-linked $\mathrm{Gal}^{\mathrm{c}}$ & 17.6 & 38.5 & 23.6 \\
\hline $1,2,5-\mathrm{Ac}_{3}-3,4,6-\mathrm{Me}_{3}$-galactitol & 2-linked $\mathrm{Gal}^{\mathrm{c}}$ & 3.6 & 0 & 3.3 \\
\hline $1,4,5-\mathrm{Ac}_{3}-2,3,6-\mathrm{Me}_{3}$-glucitol & 4-linked Glc & 17.3 & 2.3 & 11.7 \\
\hline 1,3,5-Ac $\mathrm{Ac}_{3}-2,4,6,7-\mathrm{Me}_{4}$-heptitol & 3-linked Hep ${ }^{d}$ & 11.6 & 2.6 & 1.0 \\
\hline $1,3,4,5-\mathrm{Ac}_{3}-2,6-\mathrm{Me}_{2}$-glucitol & 3,4-linked Glc ${ }^{d}$ & 0 & 3.0 & 8.5 \\
\hline $1,4,5-\mathrm{Ac}_{3}-2,3,6-\mathrm{Me}_{3}$-glucosaminitol & 4-linked GlcNAc & 7.6 & 2.0 & 12.5 \\
\hline $1,3,4,5-\mathrm{Ac}_{4}-2,6-\mathrm{Me}_{2}$-glucosaminitol & 3,4-linked GlcNAc & 0 & 0.4 & 0.6 \\
\hline
\end{tabular}

\footnotetext{
${ }^{a}$ According to fragmentation profiles and laboratory standards, at the exception of 3-linked Hep and 3,4-linked Glc, identified on the base of their mass spectrum and according to the total sugar composition.

${ }^{\mathrm{b}}$ Total ion count. Cell-specific derivatives are bolded.

${ }^{\mathrm{c}}$ Separated one from the other with the SP2380 column only

${ }^{\mathrm{d}}$ Separated one from the other with the HP5-MS column only.
} 
determine the relative abundance of bacterial LOSglycoforms [33]. In parallel, methylation linkage analyses were carried out with the de-O-acylated LOSs. Results are summarized in Table 2 and Fig. 3.

The de- $O$-acylated LOS sample of the LPS1 strain contained a main species at $2015.9 \mathrm{Da}$, fitting to the molecular composition $\mathrm{P}_{3}$-Glc-Hep ${ }_{2}-\mathrm{Kdo}_{2}$-lipid $\mathrm{A}$ as previously reported for this strain [1]. An additional species corresponding to $\mathrm{P}_{3}$-Glc-Hep $\mathrm{H}_{2}-\mathrm{Kdo}_{2}$-PEtN-lipid A (+123 Da) was also observed (Fig. 3, uppermost panel).

The spectra of the three recombinant strains H type II, LX, and LY showed progressively larger molecular weight LOS as a result of the overexpression of recombinant glycosyltransferase genes. All three strains overexpressed the genes encoding for LgtE, LgtA and LgtB, which are responsible for the synthesis of Gal $\beta-3 \mathrm{GlcNAc} \beta-3 \mathrm{Gal} \beta-4-$
Glc- $\mathrm{P}_{3}$-Glc-Hep ${ }_{2}-\mathrm{Kdo}_{2}$-lipid A by glycosylation of the truncated core present in the LPS1 strain. The MALDITOF spectra of the three strains (H type II, LX, LY) showed a common peak arising at $2542 \mathrm{Da}$ (Fig. 3) from the addition of two hexoses (Hex) and one $\mathrm{N}$ acetylhexosamine (HexNAc) to the truncated Glc-LOS of the LPS1 strain, compatible with an additional [GalGlcNAc-Gal] motif. An associated Gal $\beta-3 \mathrm{GlcNAc} \beta$ $3 \mathrm{Gal} \beta-4 \mathrm{Glc}-\mathrm{P}_{3}$-Glc-Hep ${ }_{2}-\mathrm{Kdo}_{2}$-PEtN-lipid A species was also observed (2665 Da, Fig. 3).

The chemical analysis of the $\mathrm{H}$ type II strain LOS sample. Which specifically expressed the $\alpha 1,2$-fucosyltransferase FutC in addition to LgtE, LgtA and LgtB contained a peak at 2687.5 Da corresponding to an additional fucose residue present (Fig. 3, second panel from top), matching to the carbohydrate backbone [Fuc-Gal-GlcNAc-Gal-P ${ }_{3}$-Glc-

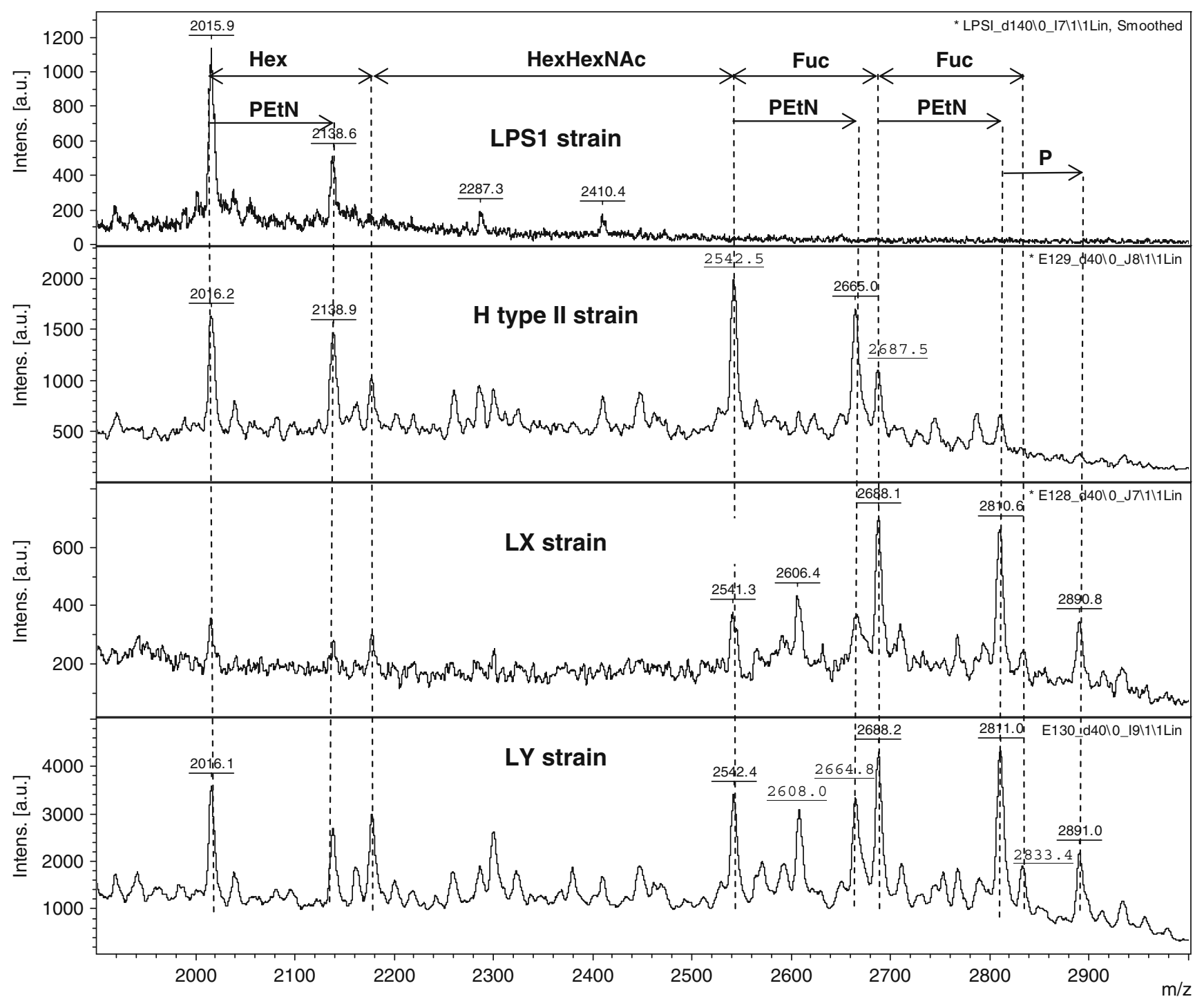

Fig. 3 Negative MALDI-TOF analysis spectra of de-O-acylated LOS from recombinant $E$. coli strains 
$\mathrm{Hep}_{2}-\mathrm{Kdo}_{2}$-lipidA]. The methylation analysis (Table 2) confirmed the presence of a terminal fucose residue as well as 2-linked galactose, characterizing the motif Fuc $\alpha$-2Gal and therefore glycoform I (Fig. 4). This is in agreement with the specificity of FutC on $\beta$-galactosides.

When the de-O-acylated LOS sample of LX strain, which specifically expressed the $\alpha 1,3$-fucosyltransferase FutA in addition to LgtE, LgtA and LgtB, was analysed by MALDI-TOF it resulted in a spectrum very similar to the one of the $\mathrm{H}$ type II strain, although the proportion of the mono-fucosylated species [Fuc-Gal-GlcNAc-Gal-P ${ }_{3}$-Glc$\mathrm{Hep}_{2}-\mathrm{Kdo}_{2}$-lipidA] (and the corresponding PEtN-lipidA glycoform) was much higher (Fig. 3, second panel from bottom). The methylation analysis revealed the presence of a high amount of 3,4-linked glucose and a low amount of 3,4-linked $N$-acetylglucosamine. This indicated a fucosylation of the $\mathrm{C} 3-\mathrm{OH}$ of GlcNAc (in the lactosaminyl motif) but on the other hand of the Glc residue (in the lactosyl motif) as well, thereby demonstrating the presence of glycoforms II and III (see Fig. 4). These data fit to the known specificity of the fucosyltransferase FutA used in this study, which was reported to have a good activity on lactosyl as well as $\mathrm{N}$-acetyllactosaminyl motifs of $\mathrm{H}$ type II acceptors [34]. A preferential fucosylation on glucose was also obtained when the same co-expressed enzymes acted

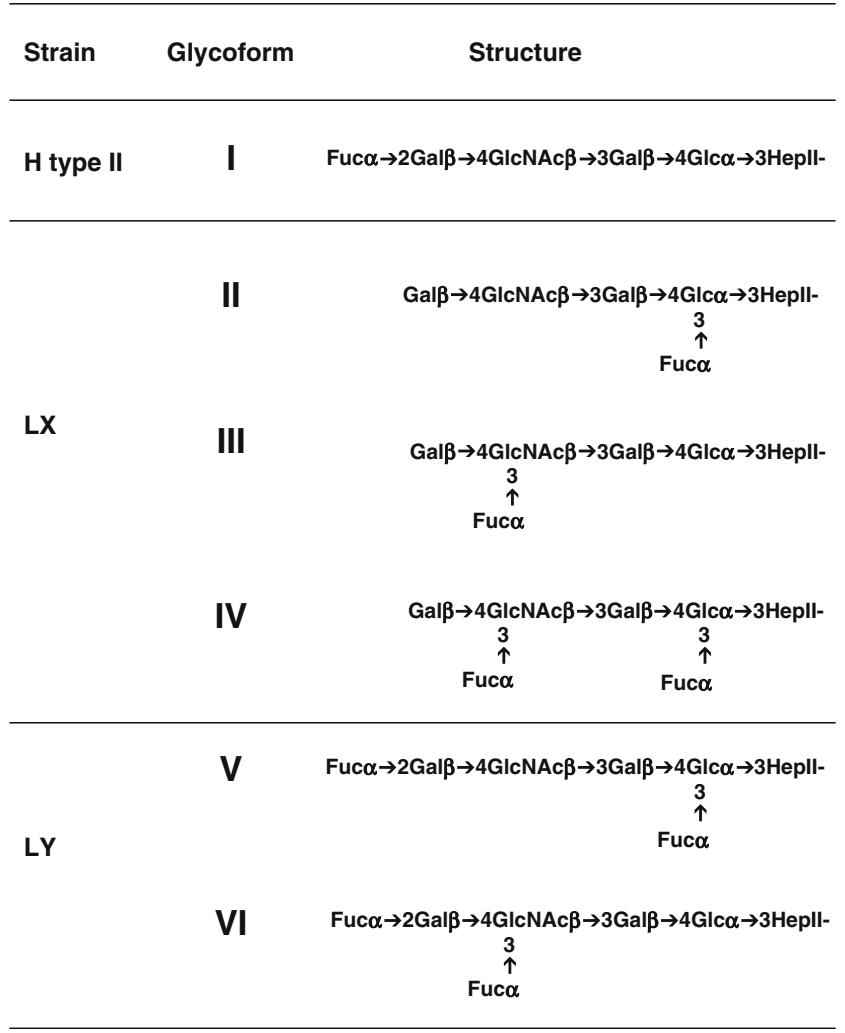

Fig. 4 Proposed chemical structures of fucosylated LOS of recombinant $E$. coli strains on free lactose as an acceptor [16]. A small glycoform at $\mathrm{m} /$ z 2838 Da (Fig. 3, second panel from bottom) corresponded to a difucosylated carbohydrate backbone $\left[\mathrm{Fuc}_{2}-\mathrm{Gal}-\right.$ GlcNAc-Gal-P 3 -Glc-Hep ${ }_{2}-\mathrm{Kdo}_{2}$-lipidA], which meant that both the Glc and the GlcNAc residue of the Gal-GlcNAcGal-P ${ }_{3}-\mathrm{Glc}_{\mathrm{Hep}}-\mathrm{Kdo}_{2}$-lipidA] backbone were fucosylated, leading to glycoform IV (Fig. 4).

The LY strain used in our study combined the two $\alpha 1,2-$ and $\alpha 1,3-$ fucosyltransferases FutC and FutA, which had been expressed separately in the strains LX and H type II. When the de-O-acylated LOS sample of the LY strain was analysed, the MALDI-TOF spectrum obtained was comparable with the spectrum of the LX strain, but showed a slight increase of difucosylated forms (Fig. 3, lowest panel). The methylation analysis revealed the combined derivative products of the $\alpha-1,2$-fucosyltransferase action (2-linked Gal) and of the $\alpha-1,3$-fucosyltransferase action (3,4-linked Glc/GlcNAc), thus corresponding to glycoforms V and VI, the last one bearing the Lewis $\mathrm{Y}$ antigen (Table 2 and Fig. 4).

\section{Discussion}

Our data show that fucosylation of the lipid A core of Escherichia coli $\mathrm{K} 12$ can be obtained by design of a suitable LOS mutant co-expressing various glycosyltransferases. This is the first report describing the endogenous fucosylation of the lipid A core of $E$ coli. The human cell surface antigen Lewis $\mathrm{Y}$ was displayed on the bacterial cell surface of the LY strain as visible in a cell-based immunoassay using a monoclonal antibody raised against Lewis Y (Fig. 1). The chemical analysis of de- $O$-acylated LOS showed that the Lewis $\mathrm{Y}$ structure was not predominant, since a major form carrying a fucose on glucose was also observed. These data can be explained by the reduced specificity of the $\alpha 1,3$-fucosyltransferase used in this study. A possibility to increase the expression of the Lewis $\mathrm{Y}$ epitope could include the use of a more specific fucosyltransferase. In this respect our bacterial system displaying fucosylated structures on the cell surface would enable researchers to sort clones (e.g. by fluorescence-activated cell sorting) exhibiting an improved Lewis $\mathrm{Y}$ expression after the molecular evolution of the $\alpha 1,3$-fucosyltransferase used. It is interesting to note that, although the $\alpha 1,3-$ fucosyltransferase employed in this study shows relaxed specificity towards the acceptor substrate, we can assume that the configuration of the oligosaccharide product created in the E. coli cells by heterologous glycosyltransferase expression is corresponding to the configuration seen in the Lewis Y epitope e.g. on human blood cells as it is unlikely that recognition by the monoclonal antibody against the Lewis $\mathrm{Y}$ epitope would not be hindered by a 
change configuration of the monosaccharides involved. Earlier studies in our lab also showed that the oligosaccharide product created by heterologous expression of the $\alpha 1,3$-fucosyltransferase as well as the other glycosyltransferases except the $\alpha 1,2$-fucosyltransferase could be shown to contain the wild type monosaccharide configuration by NMR when produced in a soluble form [15].

The strains H type II and LX synthesized the group H-type 2 and the Lewis X oligosaccharide motifs, respectively, as judged by the chemical analysis of their respective LOS. The fucosylation on LOS was detected by lectinbased cell detection assays with the fucose-binding lectin of Ralstonia solanacearum [35], but our attempt to make a specific detection with a Lewis $\mathrm{X}$ antibody was not successful.

The MALDI-TOF analysis suggests that all recombinant strains possess PEtN-modified lipid A core species. The PEtN substitution is normally not important in Escherichia coli $\mathrm{K} 12$, but has been associated with the outer membrane adaptation to environmental stress induced by divalent cations and some antibiotics $[36,37]$. A possible explanation for the PEtN substitutions visible in our strains is that the chimeric glycosylation of the outer core affects the outer membrane stability, resulting in an induction of PEtN substitution of the lipid A core.

This work is a step forward in the glyco-mimicry engineering of bacteria. Lewis antigens are common host targets for pathogens to bind to, such as pathogenic $C$. jejuni, and $P$. aeruginosa $[11,12]$. Competition experiments with our fucose-displaying non-pathogenic strains therefore might be a prelude to the design of new probiotic-based therapies. Furthermore, these strains present the researcher with the possibility to change the specificity of glycosyltransferases by molecular evolution and subsequent testing with lectins and cell sorting. In addition, our strains could in the future be used to study the interaction between host receptors with the mentioned carbohydrate structures on non-pathogenic bacteria, thereby enabling us to dissect the effects mediated by the carbohydrate structures from the ones mediated by other bacterial virulence factors.

Acknowledgements We thank Bernard Brasme and Stéphanie Beffy for performing the mass analyses. This work was supported by a SNF grant (31003A_127098/1) to MA and a Marie Curie Early Stage Research Training Fellowship of the European Community's Sixth Framework Programme (MEST-CT-2004-5033) to EY.

\section{References}

1. Ilg, K., Yavuz, Y., Maffioli, C., Priem, B., Aebi, M.: Glycomimicry: display of the GM3 sugar epitope on Escherichia coli and Salmonella enterica sv Typhimurium. Glycobiology 20, 12891297 (2010)
2. Raetz, C.R., Whitfield, C.: Lipopolysaccharide endotoxins. Annu. Rev. Biochem. 71, 635-700 (2002)

3. Valvano, M.A.: Export of O-specific lipopolysaccharide. Front. Biosci. 8, s452-471 (2003)

4. Paton, A.W., Morona, R., Paton, J.C.: A new biological agent for treatment of Shiga toxigenic Escherichia coli infections and dysentery in humans. Nat. Med. 6, 265-270 (2000)

5. Paton, A.W., Jennings, M.P., Morona, R., Wang, H., Focareta, A., Roddam, L.F., Paton, J.C.: Recombinant probiotics for treatment and prevention of enterotoxigenic Escherichia coli diarrhea. Gastroenterology 128, 1219-1228 (2005)

6. Morona, J.K., Paton, J.C., Miller, D.C., Morona, R.: Tyrosine phosphorylation of CpsD negatively regulates capsular polysaccharide biosynthesis in streptococcus pneumoniae. Mol. Microbiol. 35, 1431-1442 (2000)

7. Bos, M.P., Tefsen, B., Geurtsen, J., Tommassen, J.: Identification of an outer membrane protein required for the transport of lipopolysaccharide to the bacterial cell surface. Proc. Natl Acad. Sci. USA 101, 9417-9422 (2004)

8. Sperandeo, P., Cescutti, R., Villa, R., Di Benedetto, C., Candia, D., Dehò, G., Polissi, A.: Characterization of lptA and lptB, two essential genes implicated in lipopolysaccharide transport to the outer membrane of Escherichia coli. J. Bacteriol. 189, 244-53 (2007)

9. Sperandeo, P., Lau, F.K., Carpentieri, A., De Castro, C., Molinaro, A., Dehò, G., Silhavy, T.J., Polissi, A.: Functional analysis of the protein machinery required for transport of lipopolysaccharide to the outer membrane of Escherichia coli. J. Bacteriol. 190, 44604469 (2008)

10. Phillips, N.J., Miller, T.J., Engstrom, J.J., Melaugh, W., McLaughlin, R., Apicella, M.A., Gibson, B.W.: Characterization of chimeric lipopolysaccharides from Escherichia coli strain JM109 transformed with lipooligosaccharide synthesis genes (lsg) from Haemophilus influenzae. J. Biol. Chem. 275, 4747-4758 (2000)

11. Ruiz-Palacios, G.M., Cervantes, L.E., Ramos, P., ChavezMunguia, B., Newburg, D.S.: Campylobacter jejuni binds intestinal $\mathrm{H}(\mathrm{O})$ antigen (Fuc alpha 1, 2Gal beta 1, 4GlcNAc), and fucosyloligosaccharides of human milk inhibit its binding and infection. J. Biol. Chem. 278, 14112-20 (2003)

12. Wu, A.M., Wu, J.H., Singh, T., Liu, J.H., Tsai, M.S., GilboaGarber, N.: Interactions of the fucose-specific Pseudomonas aeruginosa lectin, PA-IIL, with mammalian glycoconjugates bearing polyvalent Lewis(a) and $\mathrm{ABH}$ blood group glycotopes. Biochimie 88, 1479-92 (2006)

13. Priem, B., Gilbert, M., Wakarchuk, W.W., Heyraud, A., Samain, E.: A new fermentation process allows large-scale production of human milk oligosaccharides by metabolically engineered bacteria. Glycobiology 12, 235-240 (2002)

14. Drouillard, S., Driguez, H., Samain, E.: Large-scale synthesis of Hantigen oligosaccharides by expressing Helicobacter pylori alpha1, 2-fucosyltransferase in metabolically engineered Escherichia coli cells. Angew. Chem. Int. Ed Engl. 45, 1778-1780 (2006)

15. Dumon, C., Bosso, C., Utille, J.P., Heyraud, A., Samain, E.: Production of Lewis $\mathrm{x}$ tetrasaccharides by metabolically engineered Escherichia coli. Chembiochem 7, 359-365 (2006)

16. Dumon, C., Priem, B., Martin, S.L., Heyraud, A., Bosso, C., Samain, E.: In vivo fucosylation of lacto-N-neotetraose and lacto$\mathrm{N}$-neohexaose by heterologous expression of Helicobacter pylori alpha-1, 3 fucosyltransferase in engineered Escherichia coli. Glycoconj. J. 18, 465-474 (2001)

17. Randriantsoa, M. Synthèse microbiologique des antigènes glucidiques des groupes sanguins. 2008. PhD thesis, University of Grenoble, France

18. Wang, G., Ge, Z., Rasko, D.A., Taylor, D.E.: Lewis antigens in Helicobacter pylori: biosynthesis and phase variation. Mol. Microbiol. 36, 1187-1196 (2000) 
19. Boghaert, E.R., Sridharan, L., Armellino, D.C., Khandke, K.M., DiJoseph, J.F., Kunz, A., Dougher, M.M., Jiang, F., Kalyandrug, L.B., Hamann, P.R., Frost, P., Damle, N.K.: Antibody-targeted chemotherapy with the calicheamicin conjugate hu3S193-N-acetyl gamma calicheamicin dimethyl hydrazide targets Lewis y and eliminates Lewis y-positive human carcinoma cells and xenografts. Clin. Cancer Res. 10, 4538-4549 (2004)

20. Link, A.J., Phillips, D., Church, G.M.: Methods for generating precise deletions and insertions in the genome of wild-type Escherichia coli: application to open reading frame characterization. J. Bacteriol. 179, 6228-6237 (1997)

21. Hanahan, D.: Studies on transformation of Escherichia coli with plasmids. J. Mol. Biol. 166, 557-580 (1993)

22. Yanisch-Perron, C., Vieira, J., Messing, J.: Improved M13 phage cloning vectors and host strains: nucleotide sequences of the M13mp18 and pUC19 vectors. Gene 33, 103-119 (1985)

23. Antoine, T., Priem, B., Heyraud, A., Greffe, L., Gilbert, M., Wakarchuk, W.W., Lam, J.S., Samain, E.: Large-scale in vivo synthesis of the carbohydrate moieties of gangliosides GM1 and GM2 by metabolically engineered Escherichia coli. Chembiochem 4, 406-412 (2003)

24. Cottaz, S., Samain, E.: Genetic engineering of Escherichia coli for the production of NI, NII-diacetylchitobiose (chitinbiose) and its utilization as a primer for the synthesis of complex carbohydrates. Metab. Eng. 7, 311-317 (2005)

25. Martinez, E., Bartolome, B., de la Cruz, F.: pACYC184-derived cloning vectors containing the multiple cloning site and lacZ alpha reporter gene of pUC8/9 and pUC18/19 plasmids. Gene $\mathbf{6 8}, 159$ $162(1988)$

26. Tsai, C.M., Frasch, C.E.: A sensitive silver stain for detecting lipopolysaccharides in polyacrylamide gels. Anal. Biochem. 119, 115-119 (1982)

27. Galanos, C., Luderitz, O., Westphal, O.: A new method for the extraction of R lipopolysaccharides. Eur. J. Biochem. 9, 245-249 (1969)

28. Qureshi, N., Takayama, K., Ribi, E.: Purification and structural determination of nontoxic lipid A obtained from the lipopolysaccharide of Salmonella typhimurium. J. Biol. Chem. 257, 11808$11815(1982)$
29. Verostek, M.F., Lubowski, C., Trimble, R.B.: Selective organic precipitation/extraction of released $\mathrm{N}$-glycans following largescale enzymatic deglycosylation of glycoproteins. Anal. Biochem. 278, 111-122 (2000)

30. Hakomori, S.: A rapid permethylation of glycolipid, and polysaccharide catalyzed by methylsulfinyl carbanion in dimethyl sulfoxide. J. Biochem. 55, 205-208 (1964)

31. Piekarowicz, A., Stein, D.C.: Biochemical properties of Neisseria gonorrhoeae LgtE. J. Bacteriol. 184, 6410-6406 (2002)

32. Wakarchuk, W., Martin, A., Jennings, M.P., Moxon, E.R., Richards, J.C.: Functional relationships of the genetic locus encoding the glycosyltransferase enzymes involved in expression of the lacto-N-neotetraose terminal lipopolysaccharide structure in Neisseria meningitidis. J. Biol. Chem. 271, 19166-73 (1996)

33. Gibson, B.W., Engstrom, J.J., John, C.M., Hines, J.W., Falick, W. H.: Characterization of bacterial lipooligosaccharides by delayed extraction matrix-assisted laser desorption ionization time-of-flight mass spectrometry. J. Am. Soc. Mass Spec. 8, 645-658 (1997)

34. de Vries, T., Srnka, C.A., Palcic, M.M., Swiedler, S.J., van den Eijnden, D.H., Macher, B.A.: Acceptor specificity of different length constructs of human recombinant alpha 1, 3/4-fucosyltransferases. Replacement of the stem region and the transmembrane domain of fucosyltransferase $\mathrm{V}$ by protein A results in an enzyme with GDPfucose hydrolyzing activity. J. Biol. Chem. 270, 8712-8722 (1995)

35. Sudakevitz, D., Imberty, A., Gilboa-Garber, N.: Production, properties and specificity of a new bacterial L-fucose- and D-arabinosebinding lectin of the plant aggressive pathogen Ralstonia solanacearum, and its comparison to related plant and microbial lectins. J. Biochem. 132, 353-358 (2002)

36. Kanipes, M.I., Lin, S., Cotter, R.J., Raetz, C.R.: Ca2+-induced phosphoethanolamine transfer to the outer 3-deoxy-D-mannooctulosonic acid moiety of Escherichia coli lipopolysaccharide. A novel membrane enzyme dependent upon phosphatidylethanolamine. J. Biol. Chem. 276, 1156-1163 (2001)

37. Kim, S.H., Jia, W., Parreira, V.R., Bishop, R.E., Gyles, C.L.: Phosphoethanolamine substitution in the lipid A of Escherichia coli O157: H7 and its association with PmrC. Microbiology 152, 657-666 (2006) 